\title{
White Matter Disruption and Connected Speech in Non-Fluent and Semantic Variants of Primary Progressive Aphasia
}

\author{
Karine Marcotte ${ }^{a-c} \quad$ Naida L. Graham ${ }^{a} d \quad$ Kathleen C. Fraser ${ }^{e}$ \\ Jed A. Meltzer ${ }^{d, f-h}$ David F. Tang-Wai ${ }^{i, j}$ Tiffany W. Chow ${ }^{f, i, k}$ \\ Morris Freedman ${ }^{f, l, m}$ Carol Leonard d, h, n Sandra E. Black ${ }^{a, f, h, i, o-q}$ \\ Elizabeth Rochon ${ }^{a}, \mathrm{~d}, \mathrm{~h}, \mathrm{r}$ \\ ${ }^{a}$ Toronto Rehabilitation Institute - University Health Network, Toronto, ON, Canada; \\ bÉcole d'orthophonie et d'audiologie, Faculté de médecine, Université de Montréal, \\ Montréal, QC, Canada; 'Centre de recherche de l'Hôpital du Sacré-Cœur de Montréal, \\ Montreal, QC, Canada; ${ }^{\mathrm{d} D e p a r t m e n t}$ of Speech-Language Pathology, Faculty of Medicine,

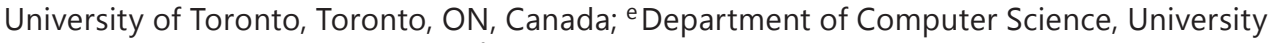

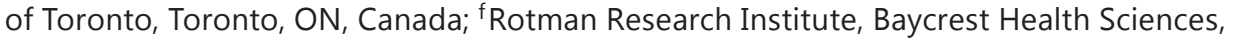 \\ Toronto, ON, Canada; 9 Department of Psychology, University of Toronto, Toronto, ON,

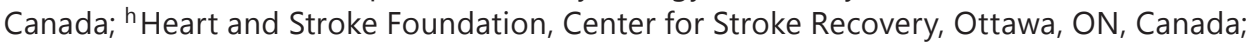 \\ 'Department of Medicine (Neurology), University of Toronto, Toronto, ON, Canada; \\ jUniversity Health Network Memory Clinic, Toronto Western Hospital, Toronto, ON, Canada; \\ kDepartment of Clinical Neurology, University of Southern California, Los Angeles, CA, USA; \\ 'Department of Medicine, Division of Neurology, Baycrest Health Sciences, University of \\ Toronto, and Mt. Sinai Hospital, Toronto, ON, Canada; mSam and Ida Ross Memory Clinic, \\ Baycrest Health Sciences, Toronto, ON, Canada; ${ }^{n}$ School of Rehabilitation Sciences, Faculty \\ of Health Sciences, University of Ottawa, Ottawa, ON, Canada; ' Institute of Medical Science,

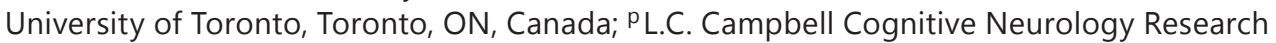 \\ Unit, Sunnybrook Health Sciences Centre, Toronto, ON, Canada; ${ }^{9}$ Brain Sciences Research \\ Program, Sunnybrook Research Institute, Toronto, ON, Canada; ${ }^{r}$ Rehabilitation Sciences \\ Institute, University of Toronto, Toronto, ON, Canada
}

\section{Keywords}

Connected speech · Non-fluent variant - Diffusion tensor imaging · Primary progressive aphasia $\cdot$ Semantic variant

\section{Abstract}

Differential patterns of white matter disruption have recently been reported in the non-fluent (nfvPPA) and semantic (svPPA) variants of primary progressive aphasia (PPA). No single measure is sufficient to distinguish between the PPA variants, but connected speech allows for the quantification of multiple measures. The aim of the present study was to further investigate the white matter correlates associated with connected speech features in PPA. We examined the relationship between white matter metrics and connected speech deficits using an auto- 
mated analysis of transcriptions of connected speech and diffusion tensor imaging in language-related tracts. Syntactic, lexical, and semantic features were automatically extracted from transcriptions of topic-directed interviews conducted with groups of individuals with nfvPPA or svPPA as well as with a group of healthy controls. A principal component analysis was performed in order to reduce the number of language measures and yielded a five-factor solution. The results indicated that nfvPPA patients differed from healthy controls on a syntactic factor, and svPPA patients differed from controls on two semantic factors. However, the patient groups did not differ on any factor. Moreover, a correlational analysis revealed that the lexical richness factor was significantly correlated with radial diffusivity in the left inferior longitudinal fasciculus, which suggests that semantic deficits in connected speech reflect a disruption of this ventral pathway, and which is largely consistent with the results of previous studies. Using an automated approach for the analysis of connected speech combined with probabilistic tractography, the present findings demonstrate that nfvPPA patients are impaired relative to healthy controls on syntactic measures and have increased radial diffusivity in the left superior longitudinal fasciculus, whereas the svPPA group was impaired on lexicosemantic measures relative to controls and showed increased radial diffusivity in the uncinate and inferior longitudinal fasciculus bilaterally.

(C) 2017 The Author(s)

Published by S. Karger AG, Basel

\section{Introduction}

Primary progressive aphasia (PPA) is an acquired, progressive language impairment, which results from a neurodegeneration of frontotemporal and/or temporoparietal brain regions $[1,2]$. The numerous studies that have examined single-word production in PPA have documented clear impairments in naming and reading [e.g. 3, 4-7], helping to elucidate the nature of the language impairments in the semantic (svPPA) and the non-fluent variants of PPA (nfvPPA). However, impairments in connected speech (i.e., discourse production) are also prevalent and can have devastating effects on social interactions [8], which could lead to a loss of independence after the onset of symptoms [9]. Moreover, the relationship between single-word naming and abilities at the level of connected speech is not straight-forward. Yet, deficits at the level of connected speech have only begun to be systematically investigated. For instance, it has been found that good performance on single-word naming tasks does not necessarily predict an ability to produce connected speech [10-12].

The evaluation of connected speech of individuals with PPA allows a detailed and naturalistic assessment of the integrity of both the syntactic and semantic systems in these patients. Connected speech in patients with nfvPPA is most consistently associated with simplified syntax, shorter utterances, and increased errors [13-16]. Connected speech of individuals with svPPA is typically fluent, but marked by word-finding difficulty, and, as the disease progresses, a reduced frequency of content words, the use of vague terms, semantic paraphasias, and circumlocutions. Concerning syntactic production in svPPA, Ash et al. [17] and Kavé et al. [18] reported little deviation from normal syntactic patterns of narrative speech, but other studies have reported simplified grammatical structure and occasional paragrammatic errors $[16,19-22]$. Thus, the possibility of syntactic impairment in svPPA remains open.

To our knowledge, so far only seven studies have provided detailed quantification and comparison of elicited speech samples between svPPA and nfvPPA [15, 16, 20, 23-26]. These studies reported significant differences mostly between nfvPPA and healthy controls in grammatical and fluency measures $[15,23,25,26]$ and between svPPA and healthy controls in lexico-semantic features $[27,28]$. A comparison of the two variants has yielded inconsistent 
findings, except that speech rate seems to reliably distinguish svPPA and nfvPPA $[15,16,23$, $24,26]$.

The advent of neuroimaging techniques has greatly contributed to the understanding and diagnosis of PPA. A small number of recent studies have shown that language processing depends not only on grey matter, but also on the white matter fibre bundles that connect the language-related cortical regions, and most have focused on the dorsal and ventral language pathways [29-35]. Generally, damage was found in the dorsal pathway (i.e. the superior longitudinal fasciculus; SLF), in both the nfvPPA and logopenic PPA variants, although changes were more widespread in nfvPPA. Conversely, svPPA was more associated with ventral changes, specifically in the uncinate and the inferior longitudinal fasciculus (ILF). Damage to the arcuate component of the SLF has also been reported in SvPPA.

To our knowledge, only four studies have investigated the relationship between language measures and diffusion tensor imaging (DTI) metrics [36-39]. Wilson et al. [39] showed that damage to the SLF, including the arcuate component, predicted syntactic processing deficits (both in comprehension and production), while damage to the ventral tracts, which included the extreme capsule fibre system and the uncinate, was not associated with syntactic deficits. Catani et al. [36] found that frontal aslant metrics correlated with speech fluency, whereas uncinate metrics correlated with semantic processing scores. Interestingly, this frontal fibre bundle was particularly damaged in nfvPPA. More recently, Mandelli et al. [37] reported significant correlations between fractional anisotropy (FA) in the fibre bundles connecting the left premotor, inferior frontal, and supplementary motor area and motor speech impairments, whereas FA in the left ventral tracts was correlated with semantic processing.

The aim of the present study was to further investigate the relationship between connected speech deficits and DTI metrics in known language-related tracts in svPPA and nfvPPA. Connected speech deficits were automatically identified using natural languageprocessing software [20] to enable an evaluation of a larger number of linguistic features than that usually included in a single study. These variables were then reduced using principal components analysis (PCA) to a small number of coherent linguistic domains, which were, in turn, correlated with DTI metrics.

\section{Materials and Methods}

\section{Participants}

Twenty-five individuals with a diagnosis of nfvPPA or svPPA and 18 age- and educationmatched healthy controls participated in the study. The patients were recruited through four memory clinics in Toronto, ON, Canada, and an experienced behavioural neurologist diagnosed each of them. The control participants were recruited from a volunteer pool. All participants were native speakers of English or completed some of their education in English. Exclusion criteria were (1) a known history of drug or alcohol abuse, and (2) a history of another neurological and/or major psychiatric illness. The Research Ethics Boards at all hospitals involved in recruitment as well as the Research Ethics Board at the University of Toronto, ON, Canada, approved the study. Written informed consent was obtained from all participants.

Patients were diagnosed with PPA and classified according to variant based on the assessment by a multidisciplinary team and according to consensus criteria [40]. Table 1 presents demographic and volumetric information as well as mean neuropsychological and language evaluation scores for both patient groups as well as for the healthy control group. A subset of the patient and control participants reported in this study was reported in Schwindt et al. [35] and Fraser et al. [20]. Table 1 shows that, as expected, svPPA patients performed 
Marcotte et al.: White Matter Disruption and Connected Speech

Table 1. Demographic and neuropsychological data for each participant group

\begin{tabular}{|c|c|c|c|c|}
\hline & $\begin{array}{l}\text { Controls } \\
(n=18)\end{array}$ & $\begin{array}{l}\text { nfvPPA } \\
(n=13)\end{array}$ & $\begin{array}{l}\text { svPPA } \\
(n=12)\end{array}$ & $\begin{array}{l}\text { Group } \\
\text { effect }\end{array}$ \\
\hline \multicolumn{5}{|l|}{ Demographic information } \\
\hline Age, years & $69.6(9.2)$ & $65.2(10.6)$ & $68.7(7.3)$ & ns \\
\hline Education, years & $16.9(4.0)$ & $13.5(2.6)$ & $18.1(5.4)$ & ns \\
\hline Females/Males & $8 / 10$ & $6 / 7$ & $4 / 8$ & \\
\hline Handedness & $18 \mathrm{R}$ & $12 \mathrm{R} / 1 \mathrm{~L}$ & $11 \mathrm{R} / 1 \mathrm{~L}$ & \\
\hline \multicolumn{5}{|l|}{ Volumetric information } \\
\hline Intracranial volume, $\times 10^{3} \mathrm{~mm}^{3}$ & $604.6(63.1)$ & $568.4(59.6)$ & $513.7(53.4)^{\mathrm{a}}$ & *** \\
\hline Normalized brain volume, $\times 10^{3} \mathrm{~mm}^{3}$ & $1,234.7(70.0)$ & $1,163.1(73.1)^{\mathrm{a}}$ & $1,118.3(89.9)^{\mathrm{a}}$ & $* * *$ \\
\hline \multicolumn{5}{|l|}{ General cognitive function } \\
\hline Mini-Mental State Examination (max. score: 30) & $28.8(1.0)$ & $22.7(7.1)^{\mathrm{a}}$ & $19.9(9.1)^{\mathrm{a}}$ & $* * *$ \\
\hline Montreal Cognitive Assessment (max. score: 30) & $26.4(2.4)$ & $16.5(6.7)^{\mathrm{a}}$ & $15.2(7.7)^{\mathrm{a}}$ & *** \\
\hline Dementia Rating Scale (max. score: 144) & $142.1(1.9)$ & $116.3(26.4)^{\mathrm{a}}$ & $99.0(27.1)^{\mathrm{a}, \mathrm{b}}$ & $* * *$ \\
\hline \multicolumn{5}{|l|}{ Language production } \\
\hline Boston Naming Test (max. score: 60 ) & $55.1(4.9)$ & $37.2(16.1)^{\mathrm{a}}$ & $11.3(10.8)^{\mathrm{a}, \mathrm{b}}$ & $* * *$ \\
\hline Semantic fluency - Animals & $21.1(5.1)$ & $11.1(7.1)^{\mathrm{a}}$ & $4.6(3.9)^{a, b}$ & $* * *$ \\
\hline Orthographic fluency - FAS & $46.6(14.2)$ & $19.7(12.0)^{\mathrm{a}}$ & $14.4(11.1)^{\mathrm{a}}$ & $* * *$ \\
\hline Verb story completion task grammaticality (max. score: 66) & $62.4(3.4)$ & $33.3(18.7)^{\mathrm{a}}$ & $50.2(17.6)$ & $* * *$ \\
\hline \multicolumn{5}{|l|}{ Language Comprehension } \\
\hline Test for Reception of Grammar (max. score: 80) & $78.1(1.7)$ & $59.2(16.0)^{\mathrm{a}}$ & $60.3(19.6)^{\mathrm{a}}$ & *** \\
\hline Peabody Picture Vocabulary Test (max. score: 204) & $191.4(14.1)$ & $158.2(43.9)$ & $81.7(53.5)^{\mathrm{a}, \mathrm{b}}$ & *** \\
\hline \multicolumn{5}{|l|}{ Pyramid and Palm Tree Test } \\
\hline Pictures (max. score: 52) & $50.7(0.8)$ & $46.7(5.0)$ & $40.8(8.4)^{\mathrm{a}, \mathrm{b}}$ & $* * *$ \\
\hline Words (max. score: 52) & $50.8(1.8)$ & $46.8(3.7)$ & $39.9(8.5)^{a, b}$ & *** \\
\hline \multicolumn{5}{|l|}{ Visuospatial } \\
\hline Copy of Rey Complex Figure (max. score: 36) & $32.9(3.0)$ & $28.8(7.9)$ & $30.2(9.1)$ & ns \\
\hline \multicolumn{5}{|l|}{ Visual Object and Space Perception } \\
\hline Cube analysis subtest (max. score: 10) & $8.9(1.9)$ & $8.7(1.8)$ & $8.9(2.5)$ & ns \\
\hline Dot Counting analysis subtest (max. score: 10 ) & $10.0(0)$ & $9.2(1.4)$ & $9.5(1.2)$ & ns \\
\hline Object Decision subtest (max. score: 20) & $17.5(2.0)$ & $16.0(2.5)$ & $14.5(3.5)^{\mathrm{a}}$ & * \\
\hline \multicolumn{5}{|l|}{ Verbal Working Memory } \\
\hline Digit Span: Forward & $7.2(.8)$ & $5.2(1.6)^{a}$ & $5.8(1.8)^{\mathrm{a}}$ & *** \\
\hline Digit Span: Backward & $4.8(1.0)$ & $3.5(0.9)^{\mathrm{a}}$ & $3.9(1.4)$ & *** \\
\hline \multicolumn{5}{|l|}{ Non-Verbal Working Memory } \\
\hline Pointing Span: Forward & $5.3(1.1)$ & $4.5(1.2)$ & $4.8(1.3)$ & ns \\
\hline Pointing Span: Backward & $4.5(.8)$ & $4.4(1.6)$ & $4.8(1.4)$ & ns \\
\hline \multicolumn{5}{|l|}{ Non-Verbal Memory } \\
\hline 30-min recall of Rey Complex Figure (max. score: 36 ) & $16.4(6.2)$ & $14.4(7.9)$ & $10.7(9.1)$ & ns \\
\hline Recognition Memory Test: Faces (max. score: 25 ) & $24.3(1.0)$ & $22.2(2.8)$ & $18.1(3.6)^{\mathrm{a}, \mathrm{b}}$ & *** \\
\hline \multicolumn{5}{|l|}{ Non-Verbal Reasoning } \\
\hline Raven's Coloured Progressive Matrices (max. score: 36) & $32.3(3.7)$ & $24.2(9.3)^{\mathrm{a}}$ & $29.6(7.4)$ & * \\
\hline \multicolumn{5}{|l|}{ Executive Functioning } \\
\hline Wisconsin Card Sorting Test - categories passed & $3.8(1.2)$ & $2.5(1.8)^{\mathrm{a}}$ & $3.3(1.7)$ & * \\
\hline
\end{tabular}

Values shown are means (standard deviations). Asterisks denote significant effect of group on one-way ANOVAs at $* p<0.05,{ }^{* * *} p \leq$ 0.005 ; ns, not significant. ${ }^{a}$ Significantly different from controls; ${ }^{\mathrm{b}}$ significantly different from nfvPPA.

more poorly than controls and nfvPPA patients in tasks measuring lexical and semantic processing, such as the Boston Naming Test [41], Peabody Picture Vocabulary Test [PPVT; 42], and Pyramids and Palm Trees Test [43]. Conversely, nfvPPA patients had effortful speech, and produced fewer grammatically correct sentences in a verb story completion task [44, 45]. They were also impaired relative to controls on the Test for the Reception of Grammar [46].

\section{Connected Speech Task}

Connected speech samples were obtained via topic-directed interviews, following the method of Orange et al. [47]. Participants were asked about (1) their family, (2) their health, (3) what they do each day, (4) where they were born and raised, and (5) the jobs or work that they did. The examiner introduced the topic with a short open-ended question after which they were limited to a single simple prompt for elaboration. The participants could speak for as long as they wished. The interviews were recorded on a digital audio recorder for subse- 
quent verbatim transcription. Question 3 (what participants do each day) generated on average the greatest number of words. We chose to analyze responses to this question in order to meet a minimum requirement of 100 narrative words in each participant's connected speech sample. Where this criterion was not met with Question 3, responses to other questions were added to reach the criterion of 100 narrative words. We chose the 100-word criterion in order that each participant's speech sample would be of similar length, and so that we would be able to extract measures sensitive to length. This is compatible with other studies, which have used small speech samples and reported reliable differences between PPA patients and controls $[10,22,26,48]$. Transcription was done in accordance with the Quantitative Production Analysis [49].

\section{Analysis of Connected Speech}

A detailed description of the connected speech automated analysis process was previously reported [20]. The features automatically analyzed included 1 fluency feature, 26 syntactic complexity features, 17 lexical features, and 16 semantic features [see Table 2]. Note that in addition to the measures that we reported previously [23], three other measures (features 58-60) were added to the present study to measure lexical richness. Based on a study that investigated lexical performance in Alzheimer disease [50], Brunét's index and Honoré's statistic were added. Unlike the type-token ratio (feature 57), Brunét's index quantifies lexical richness without being sensitive to text length [51]. A lower value represents a richer vocabulary. Honoré's statistic [52] represents the proportion of words used once, relative to the total number of words used in the narrative. It is based on the notion that the larger the number of words used only once by a speaker, the richer the lexicon. Finally, we also included in the analysis the raw number of words used once. In the earlier study, we analyzed a different speech sample (Cinderella narratives, as opposed to the topic-directed interviews being analyzed here); the results of this new automated approach were tested against manual methods and the average agreement between the automated tagger and a human annotator was found to be high.

\section{Imaging Protocol}

Images were acquired using a 3.0T GE scanner with a standard eight-channel coil, at the Sunnybrook Health Sciences Centre in Toronto, ON, Canada. A high-resolution structural scan was first obtained using a three-dimensional, T1-weighted pulse sequence with TR $=8.1 \mathrm{~ms}$, $\mathrm{TE}=3.2 \mathrm{~ms}$, slices $=186$, matrix $=256 \times 192$ matrix, $\mathrm{FOV}=220 \mathrm{~mm}$, and voxel size $=1 \times 1 \times$ $1 \mathrm{~mm}$. Diffusion-weighted data were also acquired using the standard eight-channel coil, along 23 non-collinear directions with a $b$ value of 1,000 , and two unweighted images (TR = $8,800 \mathrm{~ms}, \mathrm{TE}=80 \mathrm{~ms}$, slices $=45$, matrix $=128 \times 128, \mathrm{FOV}=380 \mathrm{~mm}$, voxel size $=3 \times 3 \times$ $3 \mathrm{~mm}$ ). Two one-NEX repetitions were collected for each participant.

\section{Structural MRI Analysis}

Structural MR images were processed using FSL 4.1 (FMRIB Software Library, Oxford, UK; http://fsl.fmrib.ox.ac.uk/fsl/fslwiki/). Using Brain Extraction Tool, both T1- and diffusionweighted data were skull stripped, in order to remove all non-brain tissue, and aligned to MNI space using both linear and non-linear transformations. The output images were visually inspected with FSLview to confirm the quality of the spatial registration. Then, the T1-weighted scans were segmented into grey matter, white matter, and cerebral spinal fluid using FMRIB's Automated Segmentation Tool tissue-type segmentation.

To ensure that the PPA patients included in this study showed grey matter atrophy consistent with previous studies, we conducted a voxel-based morphometry (VBM) analysis. Structural data were analyzed with FSL-VBM [53, http://fsl.fmrib.ox.ac.uk/fsl/fslwiki/ 
Table 2. A comparison of the connected speech features of each participant group

\begin{tabular}{|c|c|c|c|c|c|}
\hline & & $\begin{array}{l}\text { Controls } \\
(n=18)\end{array}$ & $\begin{array}{l}\text { nfvPPA } \\
(n=13)\end{array}$ & $\begin{array}{l}\text { svPPA } \\
(n=12)\end{array}$ & $\begin{array}{l}\text { Group } \\
\text { effect }\end{array}$ \\
\hline \multicolumn{6}{|c|}{ Fluency } \\
\hline & Words per minute & $150.8(23.08)$ & $98.7(39.0)^{\mathrm{a}, \mathrm{b}}$ & $132.3(34.0)$ & $* * *$ \\
\hline \multicolumn{6}{|c|}{ Syntactic complexity features } \\
\hline 2 & Sentences & $10.6(1.2)$ & $15.3(5.0)^{\mathrm{a}}$ & $13.3(4.3)$ & $* * *$ \\
\hline 3 & T-units (a clause and all of its dependent clauses) ${ }^{\dagger}$ & $0.10(0.01)$ & $0.14(0.04)^{\mathrm{a}}$ & $0.12(0.03)$ & $* * *$ \\
\hline 4 & Clauses (a structure consisting of at least a subject and a finite verb) ${ }^{\dagger}$ & $0.12(0.02)$ & $0.15(0.04)^{\mathrm{a}}$ & $0.14(0.03)$ & $*$ \\
\hline 5 & Coordinate phrases (a phrase immediately before a coordinating conjunction) ${ }^{\dagger}$ & $0.021(0.014)$ & $0.025(0.015)$ & $0.025(0.014)$ & ns \\
\hline 6 & Complex nominals (a noun phrase, clause, or gerund that stands in for a noun) ${ }^{\dagger}$ & $0.087(0.023)$ & $0.075(0.022)$ & $0.072(0.015)$ & ns \\
\hline 7 & Complex T-units (a T-unit which contains a dependent clause) ${ }^{\dagger}$ & $0.026(0.016)$ & $0.021(0.017)$ & $0.023(0.012)$ & ns \\
\hline 8 & Verb phrases (a phrase consisting of at least a verb and its dependents) ${ }^{\dagger}$ & $0.16(0.04)$ & $0.18(0.03)$ & $0.18(0.03)$ & ns \\
\hline 9 & Dependent clauses (a clause which could not form a sentence on its own) ${ }^{\dagger}$ & $0.033(0.022)$ & $0.031(0.023)$ & $0.035(0.021)$ & ns \\
\hline 10 & Mean length of sentence & $10.2(1.3)$ & $7.6(2.5)^{\mathrm{a}}$ & $8.7(2.8)$ & $*$ \\
\hline 11 & Mean length of clause & $8.3(1.5)$ & $6.9(1.7)^{\mathrm{a}}$ & $7.1(1.3)$ & $*$ \\
\hline 12 & Mean length of T-unit & $10.3(1.3)$ & $7.9(2.6)^{\mathrm{a}}$ & $9.0(2.7)$ & $*$ \\
\hline 13 & Dependent clauses per clause & $0.25(0.14)$ & $0.20(0.14)$ & $0.25(0.15)$ & ns \\
\hline 14 & Dependent clauses per T-unit & $0.34(0.22)$ & $0.27(0.23)$ & $0.36(0.32)$ & ns \\
\hline 15 & Verb phrases per T-unit & $1.67(0.45)$ & $1.42(0.44)$ & $1.65(0.65)$ & ns \\
\hline 16 & Clauses per sentence & $1.25(0.20)$ & $1.11(0.30)$ & $1.22(0.34)$ & ns \\
\hline 17 & Clauses per T-unit & $1.26(0.20)$ & $1.16(0.28)$ & $1.27(0.33)$ & ns \\
\hline 18 & Complex T-units per T-unit & $0.26(0.16)$ & $0.18(0.16)$ & $0.21(0.14)$ & ns \\
\hline 19 & Coordinate phrases per T-unit & $0.22(0.15)$ & $0.22(0.18)$ & $0.24(0.18)$ & ns \\
\hline 20 & Complex nominals per T-unit & $0.89(0.27)$ & $0.62(0.33)^{\mathrm{a}}$ & $0.64(0.18)^{\mathrm{a}}$ & $*$ \\
\hline 21 & T-units per sentence & $0.99(0.05)$ & $0.96(0.04)$ & $0.96(0.11)$ & ns \\
\hline 22 & Coordinate phrases per clause & $0.18(0.13)$ & $0.19(0.13)$ & $0.19(0.11)$ & ns \\
\hline 23 & Complex nominals per clause & $0.72(0.24)$ & $0.53(0.23)^{\mathrm{a}}$ & $0.51(0.13)^{\mathrm{a}}$ & $*$ \\
\hline 24 & Tree height (height of the parse tree) & $9.40(1.10)$ & $8.13(1.47)$ & $8.95(1.72)$ & ns \\
\hline 25 & Total Yngve depth & $26.7(5.3)$ & $18.7(7.5)^{\mathrm{a}}$ & $22.0(9.4)$ & $*$ \\
\hline 26 & Max Yngve depth & $3.71(0.34)$ & $3.19(0.50)^{\mathrm{a}}$ & $3.30(0.40)^{\mathrm{a}}$ & $* * *$ \\
\hline 27 & Mean Yngve depth & $2.39(0.15)$ & $2.14(0.20)^{\mathrm{a}}$ & $2.21(0.19)^{\mathrm{a}}$ & $* * *$ \\
\hline \multicolumn{6}{|c|}{ Lexical features } \\
\hline 28 & Nouns (\# nouns/\# words) & $0.22(0.06)$ & $0.20(0.06)$ & $0.16(0.04)^{\mathrm{a}}$ & $*$ \\
\hline 29 & Verbs (\# verbs/\# words) & $0.20(0.04)$ & $0.21(0.04)$ & $0.21(0.04)$ & ns \\
\hline 30 & Noun-verb ratio (\# nouns/\# verbs) & $1.22(0.66)$ & $1.04(0.47)$ & $0.78(0.32)$ & ns \\
\hline 31 & Proportion of nouns (\# nouns/(\# nouns/\# verbs)) & $0.52(0.11)$ & $0.48(0.10)$ & $0.42(0.09)^{\mathrm{a}}$ & $*$ \\
\hline 32 & Proportion of verbs (\# verbs/(\# nouns/\# verbs)) & $0.48(0.11)$ & $0.52(0.10)$ & $0.58(0.09)^{\mathrm{a}}$ & $*$ \\
\hline 33 & Inflected verbs (\# inflected verbs/\# verbs) & $0.41(0.17)$ & $0.48(0.18)$ & $0.37(0.27)$ & ns \\
\hline 34 & Light verbs (\# light verbs/\# verbs) & $0.50(0.16)$ & $0.54(0.17)$ & $0.54(0.16)$ & ns \\
\hline 35 & Determiners (\# determiners/\# words) & $0.101(0.034)$ & $0.094(0.029)$ & $0.087(0.019)$ & ns \\
\hline 36 & Demonstratives (\# demonstratives/\# words) & $0.022(0.018)$ & $0.017(0.017)$ & $0.025(0.026$ & ns \\
\hline 37 & Prepositions (\# prepositions/\# words) & $0.119(0.031)$ & $0.091(0.038)$ & $0.093(0.034)$ & ns \\
\hline 38 & Adjectives (\# adjectives/\# words) & $0.047(0.019)$ & $0.044(0.017)$ & $0.031(0.023)$ & ns \\
\hline 39 & Adverbs (\# adverbs/\# words) & $0.068(0.039)$ & $0.076(0.038)$ & $0.103(0.024)^{\mathrm{a}}$ & $*$ \\
\hline 40 & Pronoun ratio (\# pronouns $/(\#$ nouns + \# pronouns)) & $0.36(0.09)$ & $0.44(0.08)$ & $0.47(0.10)^{\mathrm{a}}$ & $*$ \\
\hline 41 & Function words (\# function words/\# words) & $0.41(0.03)$ & $0.41(0.05)$ & $0.41(0.08)$ & ns \\
\hline 42 & Closed class ratio & $0.47(0.03)$ & $0.47(0.04)$ & $0.49(0.05)$ & ns \\
\hline 43 & Verbs per sentence & $2.00(0.50)$ & $1.59(0.69)$ & $1.91(0.88)$ & ns \\
\hline 44 & Word length (mean number of letters in each word) & $3.95(0.24)$ & $3.69(0.23)^{\mathrm{a}}$ & $3.75(0.37)$ & $*$ \\
\hline \multicolumn{6}{|c|}{ Semantic features } \\
\hline 45 & Frequency (mean frequency of all words appearing in the frequency norms) & $4.82(0.15)$ & $4.90(0.15)$ & $5.01(0.19)^{\mathrm{a}}$ & $*$ \\
\hline 46 & Noun frequency (mean frequency of nouns appearing in the frequency norms) & $3.62(0.22)$ & $3.68(0.26)$ & $3.75(0.32)$ & ns \\
\hline 47 & Verb frequency (mean frequency of verbs appearing in the frequency norms) & $4.59(0.38)$ & $4.69(0.33)$ & $4.88(0.21)$ & ns \\
\hline \multirow[t]{2}{*}{48} & Imageability & & & & \\
\hline & (mean imageability of all words appearing in the imageability norms) & $476.1(49.2)$ & $472.8(46.9)$ & $462.1(74.5)$ & ns \\
\hline \multirow[t]{2}{*}{49} & Noun Imageability & & & & \multirow[t]{2}{*}{ ns } \\
\hline & (mean imageability of nouns appearing in the imageability norms) & $524.0(43.2)$ & $521.5(50.2)$ & $529.1(66.2)$ & \\
\hline \multirow[t]{2}{*}{50} & Verb imageability & & & & \multirow[t]{2}{*}{ ns } \\
\hline & (mean imageability of verbs appearing in the imageability norms) & $434.2(72.8)$ & $382.4(79.3)$ & $385.4(115.9)$ & \\
\hline \multirow[t]{2}{*}{51} & Age of acquisition & & & & \multirow[t]{2}{*}{ ns } \\
\hline & (mean age of acquisition of all words appearing in the age of acquisition norms) & $303.1(32.9)$ & $310.8(47.4)$ & $276.5(48.9)$ & \\
\hline \multirow[t]{2}{*}{52} & Noun age of acquisition & & & & \\
\hline & (mean age of acquisition of nouns appearing in the age of acquisition norms) & $317.6(39.3)$ & $328.4(59.1)$ & $296.7(74.1)$ & ns \\
\hline \multirow[t]{2}{*}{53} & Verb age of acquisition & & & & ns \\
\hline & (mean age of acquisition of verbs appearing in the age of acquisition norms) & $270.6(52.2)$ & $278.1(76.6)$ & $266.4(67.5)$ & \\
\hline 54 & Familiarity (mean familiarity of all words appearing in the familiarity norms) & $595.4(25.6)$ & $586.9(32.8)$ & $600.6(30.1)$ & ns \\
\hline 55 & Noun familiarity (mean familiarity of nouns appearing in the familiarity norms) & $586.8(32.8)$ & $583.7(35.5)$ & $584.6(55.8)$ & ns \\
\hline 56 & Verb familiarity (mean familiarity of verbs appearing in the familiarity norms) & $614.5(24.6)$ & $600.1(60.4)$ & $606.2(44.0)$ & ns \\
\hline
\end{tabular}


Table 2 (continued)

\begin{tabular}{|c|c|c|c|c|c|}
\hline & & $\begin{array}{l}\text { Controls } \\
(n=18)\end{array}$ & $\begin{array}{l}\text { nfvPPA } \\
(n=13)\end{array}$ & $\begin{array}{l}\text { svPPA } \\
(\mathrm{n}=12)\end{array}$ & $\begin{array}{l}\text { Group } \\
\text { effect }\end{array}$ \\
\hline 57 & Type-token ratio (\# unique word types/\# words) & $0.62(0.04)$ & $0.61(0.05)$ & $0.56(0.07)^{\mathrm{a}}$ & * \\
\hline 58 & 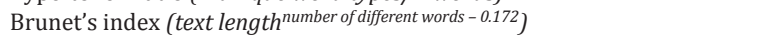 & $10.38(0.32)$ & $10.45(0.34)$ & $10.82(0.59)^{\mathrm{a}}$ & * \\
\hline \multirow[t]{2}{*}{59} & Honoré's statistic & & & & \\
\hline & (proportion of words used once, relative to the total number of words) & $1,665(404)$ & $1,657(329)$ & $1,373(306)$ & ns \\
\hline 70 & Words used once & $0.44(0.07)$ & $0.43(0.07)$ & $0.36(0.08)^{\mathrm{a}}$ & * \\
\hline
\end{tabular}

Values shown are means (standard deviations). Asterisks denote a significant effect of group on one-way ANOVAs at $* p<0.05$, $* * * p \leq 0.005$; ns, not significant.

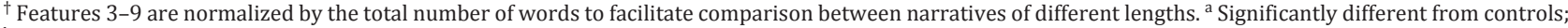
b significantly different from svPPA.

FSLVBM], which is an optimized VBM protocol [54] carried out with FSL tools [55]. First, structural images were brain-extracted and grey matter-segmented before being registered to the MNI 152 standard space using non-linear registration [56]. The resulting images were averaged and flipped along the $\mathrm{x}$-axis to create a left-right symmetric, study-specific grey matter template. Second, all native grey matter images were non-linearly registered to this study-specific template and "modulated" to correct for local expansion (or contraction) due to the non-linear component of the spatial transformation. The modulated grey matter images were then smoothed with an isotropic gaussian kernel with a sigma of $3 \mathrm{~mm}$. Finally, a voxelwise general linear model was applied using permutation-based, non-parametric testing, correcting for multiple comparisons across space.

\section{Probabilistic Tractography}

Diffusion-weighted images were analyzed with probabilistic tractography to quantify fibre integrity in language-related white matter tracts. Analyses were implemented with the FDT software package within FSL [FMRIB's Software Library; e.g. 57, 58]. First, the diffusionweighted data were registered using an affine registration to the $b 0$ volume to correct for eddy currents and motion artefacts [59]. Diffusion tensors were fit and used to generate colour-coded, FA-weighted maps, which were subsequently used to define seed regions for probabilistic tractography. Next, a probabilistic model of crossing fibres at each voxel in the brain was constructed using the Bedpostx module. This model was then combined with manually defined seed regions to identify three specific tracts: the SLF, the ILF, and the uncinate fasciculus. Regions of interest (ROIs) were defined in the native diffusion space on the FA-weighted, colour-coded maps using the seed regions proposed by Behrens et al. [60] and Galantucci et al. [33]. These ROIs were defined manually by K.M. using FSLview and double-checked by a trained research assistant. As described by Galantucci et al. [33], exclusion masks were also used to exclude fibres from neighbouring tracts. All ROIs were drawn bilaterally.

Fibre tracking was performed using the FDT (Probtrackx) module implemented in FSL, following the method previously described by Behrens et al. [60] and used by Galantucci et al. [33]. Probabilistic tractography was performed using a single-seed approach. First, all voxels within the seed masks in the diffusion space were used to generate 5,000 streamline samples, with a step length of $0.5 \mathrm{~mm}$, and a curvature threshold of 0.2 . Fibre tracking resulted in a probabilistic map of the connections of the voxels included in the starting seed with the rest of the brain, with the highest possible intensity being 5,000. All streamline samples entering into the exclusion masks were then excluded. In order to be able to compare the tracts within each group, the tract maps were normalized by dividing the number of streamline samples present by the waytotal, which corresponds to the total number of streamline 
samples that were not rejected due to exclusion masks. Moreover, a threshold equal to $40 \%$ of the 95th percentile of the distribution of the intensity values was applied to the obtained tracts, in order to correct for possible different dimensions due to the individual starting seeds [33].

\section{Tract Quantification}

Using FSLmaths, FA and radial diffusivity (RD) were calculated for each participant's tracts in diffusion space. There is growing evidence that RD is a more sensitive measure [61]. Thus, we used RD instead of the frequently used mean diffusivity. Moreover, an increase in $\mathrm{RD}$ is likely to be associated with a greater degree of myelin degeneration as documented in PPA [62]. FA was calculated from the standard deviation of the three eigenvalues [63]. RD is defined as the average of the minor eigenvalues. Spatial normalization was performed for each participant, using FLIRT in FSL. For each participant, the anatomical maps (T1) were first normalized to the standard MNI brain, using the FSL MNI152_T1_2mm template. The transformation derived from this normalization was then applied to the FA and RD maps, which were visually checked for alignment to each other and the template.

\section{Statistical Analysis}

All 60 extracted measures from connected speech transcripts were analyzed statistically to examine differences between the three groups using one-way analysis of variance (ANOVA) [see Table 2]. Post hoc comparisons were made using the Bonferroni correction. All statistical analyses were done using SPSS ${ }^{\circledR}$ v19.0, and the significance level was set at $p<0.05$.

Considering the number of language features that were extracted, PCA with varimax rotation was performed on the data from all three groups in order to reduce the number of language measures. A varimax rotation was applied in order to maximize the sum of the variances of the squared loadings. Factor loadings were accepted if they exceeded a threshold of 0.500 , which is considered a strong loading [64]. Composite indices were created from each factor derived from the PCA from factor loading scores using the SPSS default regression method. In addition, ANOVAs were computed for each component to examine differences between the groups.

Comparisons of the tracts' mean FA and RD were performed with a univariate ANCOVA, using an estimation of the normalized brain volume (NBV) as the covariate. NBV is a measure of atrophy and is a marker of disease progression. It was normalized for subject head size and was estimated with SIENAX [65], which is part of FSL [55].

\section{Language Measures}

To determine whether damage to a tract might also be predictive of measures that distinguish the two PPA variants, we included two tests that measure key impairments in each PPA variant. Impaired single-word comprehension is a defining feature in SvPPA, and this was measured using PPVT [42]. Since a syntactic processing deficit in language production is a key feature in nfvPPA, we used the sentence story completion task [44, 45], which evaluates the production of verbs in sentences; this has previously been reported to distinguish nfvPPA patients from participants with svPPA and healthy controls [66].

\section{Results}

Imaging Data

Figure 1 illustrates the results of the VBM analysis demonstrating that our nfvPPA cohort showed grey matter atrophy in the left insula $(t=4.76$, cluster size $=1,670)$ and middle 

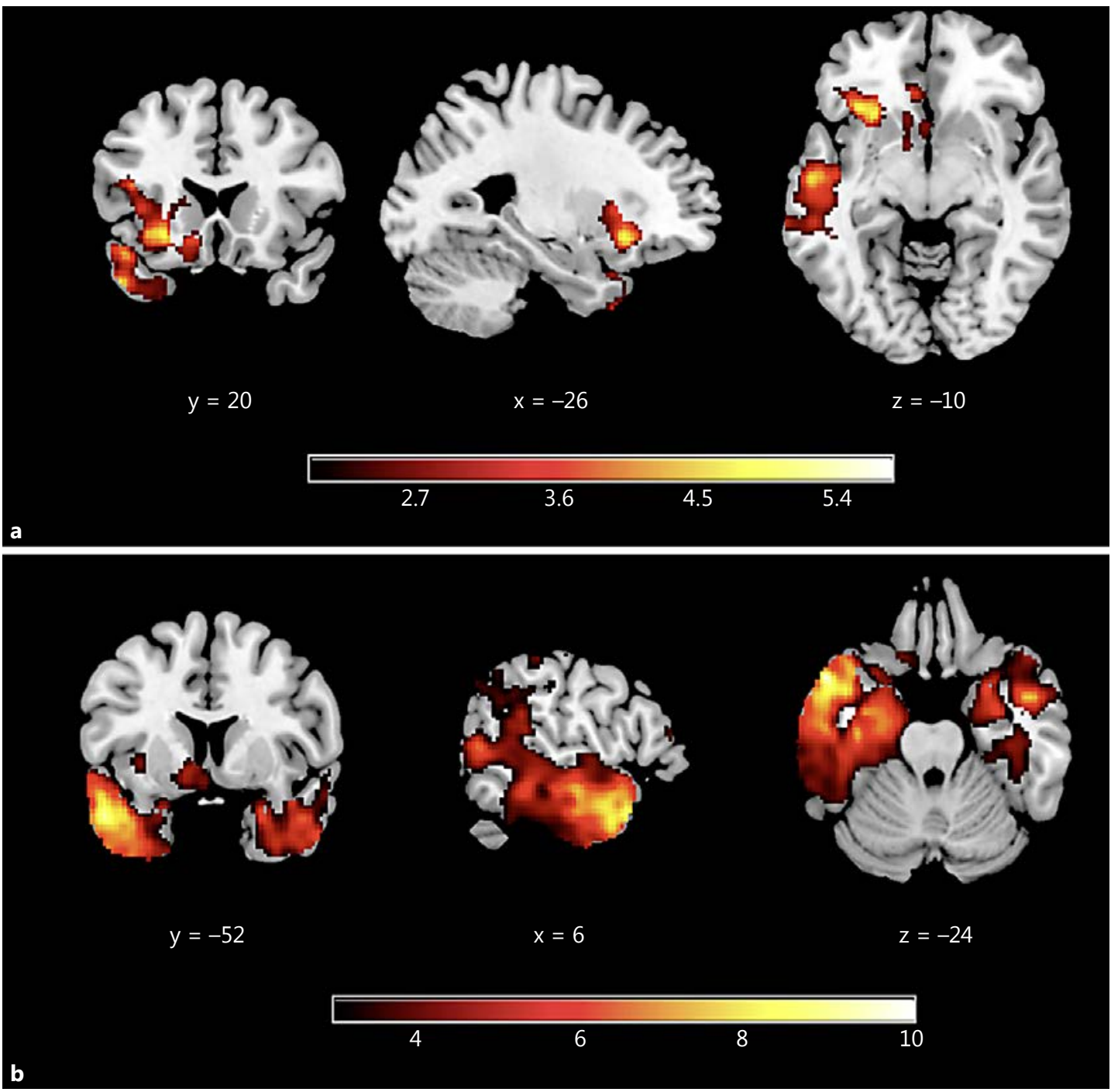

Fig. 1. VBM in nfvPPA compared with controls (a) and svPPA compared with controls (b).

temporal gyrus $(t=5.71$, cluster size $=3,925)$, whereas svPPA patients showed grey matter atrophy in the bilateral temporal areas, extending to the middle/superior areas and the insula, but more pronounced in the left hemisphere (left hemisphere: $t=6.48$, cluster size $=$ 11,277; right hemisphere: $t=5.71$, cluster size $=5,164$ ), consistent with previous studies [e.g. $1,40,67-70]$.

\section{Connected Speech Features}

As previously described, we used the criterion of 100 narrative words. Thus, the total number of words analyzed was equivalent for the three groups $(\mathrm{F}[2,40]=0.441, p=0.646)$. As in Fraser et al. [20], three separate comparison tasks were considered: (1) distinguishing between nfvPPA and controls; (2) distinguishing between svPPA and controls; and (3) distinguishing between nfvPPA and svPPA. The means and standard deviations for each feature for each group are reported in Table 2. 


\section{nfvPPA Compared to Controls}

Thirteen features were found to distinguish the nfvPPA group from the healthy controls, and all but two of these features were syntactic complexity features. The nfvPPA patients produced an increased number of sentences, T-units, and clauses. They also produced sentences, T-units, and clauses with a reduced mean length, as well as a reduced number of complex nominals per T-unit and clause. For this group, a reduction in a number of syntactic complexity measures derived from parse trees was also observed. Speech rate, as measured by the number of words per minute, was also significantly lower compared to healthy controls. Finally, mean word length was shorter for the nfvPPA patients than for the controls.

svPPA Compared to Controls

Thirteen features distinguished the svPPA group from the controls. The svPPA group produced fewer nouns and a lower pronoun ratio, an increased proportion of verbs, a lower proportion of nouns, an increased number of adverbs, and a lower type-token ratio. The mean depth and maximum depth of the parse tree as well as the number of complex nominals per clause and T-unit were significantly lower in the svPPA group. Two of the three new features that were included to measure lexical richness also distinguished the svPPA group from the controls. Specifically, Brunét's index was significantly higher for the svPPA group; whereas the number of words used once was significantly lower for the svPPA group. Each of these thirteen measures indicates that the svPPA participants had lower lexical richness in their connected speech than the healthy controls.

nfvPPA Compared to svPPA

Only one feature distinguished the nfvPPA and svPPA groups. Namely, the nfvPPA group produced fewer words per minute.

As mentioned, our previous work demonstrated that correlations between automated and manual methods of measuring features of connected speech were high across a range of measures [20]. In the present investigation, we used $t$ tests to more directly compare results obtained via the two approaches: we compared features which are included in the Quantitative Production Analysis [49], a widely used manual approach for the analysis of connected speech, with a subset of the automatically generated features. Using univariate ANOVAs (group $\times$ coding scheme; automated vs. manual), we found that the scores generated via the two methods were equivalent for all four of the measures that overlap between the manual and automated approaches (see Table $3 ; p$ values all $>0.1$ ). In summary, the overall pattern of results with respect to the groups was identical: in both the automated and manual approaches, the only connected speech feature that discriminated the two PPA variants was the number of words per minute. The interaction between group and type of coding was not significant for any of the features.

The factor structure for the 60 dependent variables from the connected speech analysis described above is displayed in Table 4. All connected speech features had at least one factor loading of 0.500 . The PCA with varimax rotation yielded a five-factor solution that accounted for $72 \%$ of the variance. Factors 1 and 2 are related to syntactic processing, whereas Factors 3-5 are related to lexico-semantic processing. Specifically, Factor 1 consists of measures that gauge sentence complexity and the amount of subordination, whereas Factor 2 consists of features that measure sentence length, coordination, and left-branching, which are syntactic complexity metrics. The third factor consists of features that measure the lexical richness of the interview. Factor 4 includes noun and verb ratios as well as pronouns and closed class ratios, and it reflects most likely the level of language production at which the lexico-semantic 
Table 3. A comparison of the connected speech features in the two patient groups using the Automated Analysis and Quantitative Production Analysis (manual coding)

\begin{tabular}{|c|c|c|c|c|}
\hline & & $\begin{array}{l}\text { nfvPPA } \\
(n=13)\end{array}$ & $\begin{array}{l}\text { svPPA } \\
(n=12)\end{array}$ & $\begin{array}{l}\text { Group } \\
\text { effect }\end{array}$ \\
\hline \multicolumn{5}{|c|}{ Automated Analysis } \\
\hline 1 & Words per minute & $98.7(39.0)^{\mathrm{a}}$ & $132.3(34.0)$ & $* * *$ \\
\hline 2 & Dependent clauses per T-unit & $0.27(0.23)$ & $0.36(0.32)$ & ns \\
\hline 3 & Pronoun ratio & $0.44(0.08)$ & $0.47(0.10)^{\mathrm{a}}$ & ns \\
\hline 4 & Proportion of verbs & $0.52(0.10)$ & $0.58(0.09)$ & ns \\
\hline \multicolumn{5}{|c|}{ Quantitative Production Analysis (manual coding) } \\
\hline 1 & Words per minute & $97.6(40.5)^{\mathrm{a}}$ & $132.2(34.1)$ & $*$ \\
\hline 2 & Embeddings & $0.35(0.33)$ & $0.35(0.29)$ & ns \\
\hline 3 & Proportion of pronouns & $0.48(0.10)^{\mathrm{a}}$ & $0.47(0.14)$ & ns \\
\hline 4 & Proportion of verbs & $0.49(0.10)^{\mathrm{a}}$ & $0.52(0.12)$ & ns \\
\hline
\end{tabular}

Values shown are means (standard deviations). Asterisks denote a significant effect of group on the $t$ test at ${ }^{*} p<0.05,{ }^{* * *} p \leq 0.005$; ns, not significant. Although the measures are similar, the two coding schemes use different labels for features 2 and 3; the corresponding features from each scheme have been assigned matching numbers. ${ }^{\text {a }}$ Significantly different from svPPA.

Table 4. Connected speech features: Factor structure

\begin{tabular}{|c|c|c|c|c|c|c|}
\hline & & $\begin{array}{l}\text { Factor } 1 \text { : } \\
\text { Sentence } \\
\text { complexity and } \\
\text { subordination }\end{array}$ & $\begin{array}{l}\text { Factor 2: } \\
\text { Sentence length } \\
\text { and syntactic } \\
\text { complexity }\end{array}$ & $\begin{array}{l}\text { Factor 3: } \\
\text { Lexical } \\
\text { richness }\end{array}$ & $\begin{array}{l}\text { Factor 4: } \\
\text { Lexical } \\
\text { access }\end{array}$ & $\begin{array}{l}\text { Factor 5: } \\
\text { Semantic } \\
\text { features }\end{array}$ \\
\hline & Fluency & & & & & \\
\hline 1 & Words per minute & 0.548 & & & & \\
\hline 2 & Sentences & -0.753 & -0.519 & & & \\
\hline 3 & T-units & -0.727 & -0.622 & & & \\
\hline 4 & Clauses & & -0.805 & & & \\
\hline 5 & Coordinate phrases & & 0.750 & & & \\
\hline 6 & Complex nominals & & & & & \\
\hline 7 & Complex T-units & 0.735 & & & & \\
\hline 8 & Verb phrases & & -0.657 & & & \\
\hline 9 & Dependent clauses & 0.764 & & & & \\
\hline 10 & Mean length of sentence & 0.784 & 0.566 & & & \\
\hline 11 & Mean length of clause & & 0.788 & & & \\
\hline 12 & Mean length of T-unit & 0.745 & 0.605 & & & \\
\hline 13 & Dependent clauses per clause & 0.839 & & & & \\
\hline 14 & Dependent clauses per T-unit & 0.849 & & & & \\
\hline 15 & Verb phrases per T-unit & 0.842 & & & & \\
\hline 16 & Clauses per sentence & 0.864 & & & & \\
\hline 17 & Clauses per T-unit & 0.802 & & & & \\
\hline 18 & Complex T-units per T-unit & 0.856 & & & & \\
\hline 19 & Coordinate phrases per T-unit & & 0.808 & & & \\
\hline 20 & Complex nominals per T-unit & 0.609 & 0.534 & & & \\
\hline 21 & T-units per sentence & & & & & \\
\hline 22 & Coordinate phrases per clause & & 0.871 & & & \\
\hline 23 & Complex nominals per clause & & 0.635 & & & \\
\hline 24 & Tree height & 0.860 & & & & \\
\hline 25 & Total Yngve depth & 0.734 & 0.610 & & & \\
\hline 26 & Max Yngve depth & & 0.753 & & & \\
\hline 27 & Mean Yngve depth & & 0.669 & & & \\
\hline
\end{tabular}


Table 4 (continued)

\begin{tabular}{|c|c|c|c|c|c|c|}
\hline & & $\begin{array}{l}\text { Factor 1: } \\
\text { Sentence } \\
\text { complexity and } \\
\text { subordination }\end{array}$ & $\begin{array}{l}\text { Factor 2: } \\
\text { Sentence length } \\
\text { and syntactic } \\
\text { complexity }\end{array}$ & $\begin{array}{l}\text { Factor 3: } \\
\text { Lexical } \\
\text { richness }\end{array}$ & $\begin{array}{l}\text { Factor 4: } \\
\text { Lexical } \\
\text { access }\end{array}$ & $\begin{array}{l}\text { Factor 5: } \\
\text { Semantic } \\
\text { features }\end{array}$ \\
\hline & Lexical features & & & & & \\
\hline 28 & Nouns & & & & -0.835 & \\
\hline 29 & Verbs & & & & & \\
\hline 30 & Noun-verb ratio & & & & -0.779 & \\
\hline 31 & Proportion of nouns & & & & -0.776 & \\
\hline 32 & Proportion of verbs & & & & 0.776 & \\
\hline 33 & Inflected verbs & & & & & 0.522 \\
\hline 34 & Light verbs & & & & & \\
\hline 35 & Determiners & & & & & \\
\hline 36 & Demonstratives & & & & & \\
\hline 37 & Prepositions & & & 0.586 & & \\
\hline 38 & Adjectives & & & 0.535 & & \\
\hline 39 & Adverbs & & & -0.620 & & \\
\hline 40 & Pronoun ratio & & & & 0.763 & \\
\hline 41 & Function words & & & & & \\
\hline 42 & Closed class ratio & & & & 0.550 & \\
\hline 43 & Verbs per sentence & 0.779 & & & & \\
\hline \multirow[t]{2}{*}{44} & Word length & & & & & \\
\hline & Semantic features & & & & & \\
\hline 45 & Frequency & & & -0.584 & & \\
\hline 46 & Noun frequency & & & & & -0.531 \\
\hline 47 & Verb frequency & & & -0.631 & & \\
\hline 48 & Imageability & & & & -0.698 & \\
\hline 49 & Noun imageability & & & & & -0.519 \\
\hline 50 & Age of acquisition & & & & & 0.810 \\
\hline 51 & Noun age of acquisition & & & & & 0.825 \\
\hline 52 & Familiarity & & & & & -0.697 \\
\hline 53 & Noun familiarity & & & & & -0.725 \\
\hline 54 & Type-token ratio & & & 0.878 & & \\
\hline 55 & Brunét's index & & & -0.838 & & \\
\hline 56 & Honoré's statistic & & & 0.716 & & \\
\hline 57 & Words used once & & & 0.835 & & \\
\hline \multicolumn{7}{|c|}{ Percent variance } \\
\hline & otal variance $=69.2 \%$ & $21.6 \%$ & $15.5 \%$ & $12.0 \%$ & $11.6 \%$ & $8.5 \%$ \\
\hline
\end{tabular}

representations are selected. Finally, Factor 5 includes variables that are known to affect word retrieval.

The means and standard deviations for each factor per group are reported in Table 5. An initial multivariate ANOVA yielded an effect of group ( $D=3.987, p<0.001)$. Individual ANOVAs yielded between-group differences for three factors, one related to syntactic processing (Factor 1: $p=0.029$ ) and two related to lexico-semantic processing (Factor 3: $p=0.008$; Factor 4: $p=0.027$ ). Post hoc comparisons showed that the nfvPPA group was significantly different from the control group on Factor 1 (syntactic factor); whereas the svPPA group was significantly different from the control group on Factors 3 and 4 (lexico-semantic factors). None of the factors distinguished the two patient groups.

\section{DTI Metrics}

Group results and differences in FA and RD of each tract are reported in Table 6. FA values are represented for each group in Figure 2 for the dorsal stream and Figure 3 for the ventral 
Table 5. Means and standard deviations of each factor from the PCA factor structure

\begin{tabular}{llll}
$\begin{array}{l}\text { Controls } \\
(n=18)\end{array}$ & $\begin{array}{l}\text { nfvPPA } \\
(n=13)\end{array}$ & $\begin{array}{l}\text { svPPA } \\
(n=12)\end{array}$ & $\begin{array}{l}\text { Group } \\
\text { effect }\end{array}$ \\
& & & \\
$0.44(0.74)$ & $-0.49(1.11)^{\mathrm{a}}$ & $-0.13(1.00)$ & $*$ \\
$0.23(0.93)$ & $-0.31(1.22)$ & $-0.01(0.81)$ & $\mathrm{ns}$ \\
$0.46(0.78)$ & $-0.02(0.97)$ & $-0.66(1.01)^{\mathrm{a}}$ & $* * *$ \\
$-0.45(1.04)$ & $0.17(0.86)$ & $0.49(0.84)^{\mathrm{a}}$ & $*$ \\
$-0.08(0.77)$ & $0.25(0.85)$ & $-0.15(1.41)$ & $\mathrm{ns}$ \\
\hline
\end{tabular}

Asterisks denote a significant effect of group on one-way ANOVAs at $*<<0.05$, *** $p \leq 0.005$; ns, not significant. a Significantly different from controls.

Table 6. Group differences in fractional anisotropy for the tracts of interest

\begin{tabular}{|c|c|c|c|c|}
\hline Tracts & Controls & nfvPPA & svPPA & Statistics \\
\hline \multicolumn{5}{|l|}{ Fractional anisotropy } \\
\hline Left superior longitudinal fasciculus & $0.43 \pm 0.04$ & $0.40 \pm 0.02$ & $0.39 \pm 0.04^{\mathrm{a}}$ & $*$ \\
\hline Right superior longitudinal fasciculus & $0.43 \pm 0.03$ & $0.41 \pm 0.04$ & $0.40 \pm 0.02$ & ns \\
\hline Left uncinate & $0.33 \pm 0.06$ & $0.30 \pm 0.06$ & $0.24 \pm 0.05^{\mathrm{a}, \mathrm{b}}$ & $* * *$ \\
\hline Right uncinate & $0.35 \pm 0.04$ & $0.33 \pm 0.03$ & $0.27 \pm 0.06^{a, b}$ & $* * *$ \\
\hline Left inferior longitudinal fasciculus & $0.43 \pm 0.03$ & $0.40 \pm 0.04$ & $0.36 \pm 0.04^{\mathrm{a}, \mathrm{b}}$ & $* * *$ \\
\hline Right inferior longitudinal fasciculus & $0.43 \pm 0.03$ & $0.42 \pm 0.03$ & $0.38 \pm 0.04^{\mathrm{a}, \mathrm{b}}$ & $* * *$ \\
\hline \multicolumn{5}{|l|}{ Radial diffusivity } \\
\hline Left superior longitudinal fasciculus & $0.66 \pm 0.05$ & $0.72 \pm 0.07^{\mathrm{a}}$ & $0.74 \pm 0.06^{\mathrm{a}}$ & $* * *$ \\
\hline Right superior longitudinal fasciculus & $0.64 \pm 0.04$ & $0.67 \pm 0.06$ & $0.68 \pm 0.03^{\mathrm{a}}$ & $*$ \\
\hline Left uncinate & $0.87 \pm 0.13$ & $1.03 \pm 0.34$ & $1.53 \pm 0.54^{\mathrm{a}, \mathrm{b}}$ & $* * *$ \\
\hline Right uncinate & $0.81 \pm 0.07$ & $0.86 \pm 0.07$ & $1.33 \pm 0.51^{\mathrm{a}, \mathrm{b}}$ & $* * *$ \\
\hline Left inferior longitudinal fasciculus & $0.73 \pm 0.04$ & $0.81 \pm 0.10$ & $1.11 \pm 0.32^{\mathrm{a}, \mathrm{b}}$ & $* * *$ \\
\hline Right inferior longitudinal fasciculus & $0.73 \pm 0.06$ & $0.77 \pm 0.07$ & $0.90 \pm 0.12^{\mathrm{a}, \mathrm{b}}$ & $* * *$ \\
\hline
\end{tabular}

Values shown are means \pm standard deviations. ${ }^{\text {a }}$ Significantly different from controls; ${ }^{\mathrm{b}}$ significantly different from nfvPPA.

stream. As with the connected speech analysis, three separate classification tasks were considered for the DTI analysis: (1) distinguishing between nfvPPA and controls; (2) distinguishing between svPPA and controls; and (3) distinguishing between nfvPPA and svPPA.

nfvPPA Compared to Controls

There were no significant differences between the nfvPPA group and the healthy controls in FA. However, the nfvPPA group showed significantly higher RD in the left SLF as compared to the healthy controls.

svPPA Compared to Controls

FA was significantly lower, whereas RD was significantly higher in the ILF and uncinate bilaterally for the svPPA group.

nfvPPA Compared to svPPA

When compared to the nfvPPA group, the svPPA group showed significantly lower FA values and higher RD in the ILF and uncinate bilaterally. 


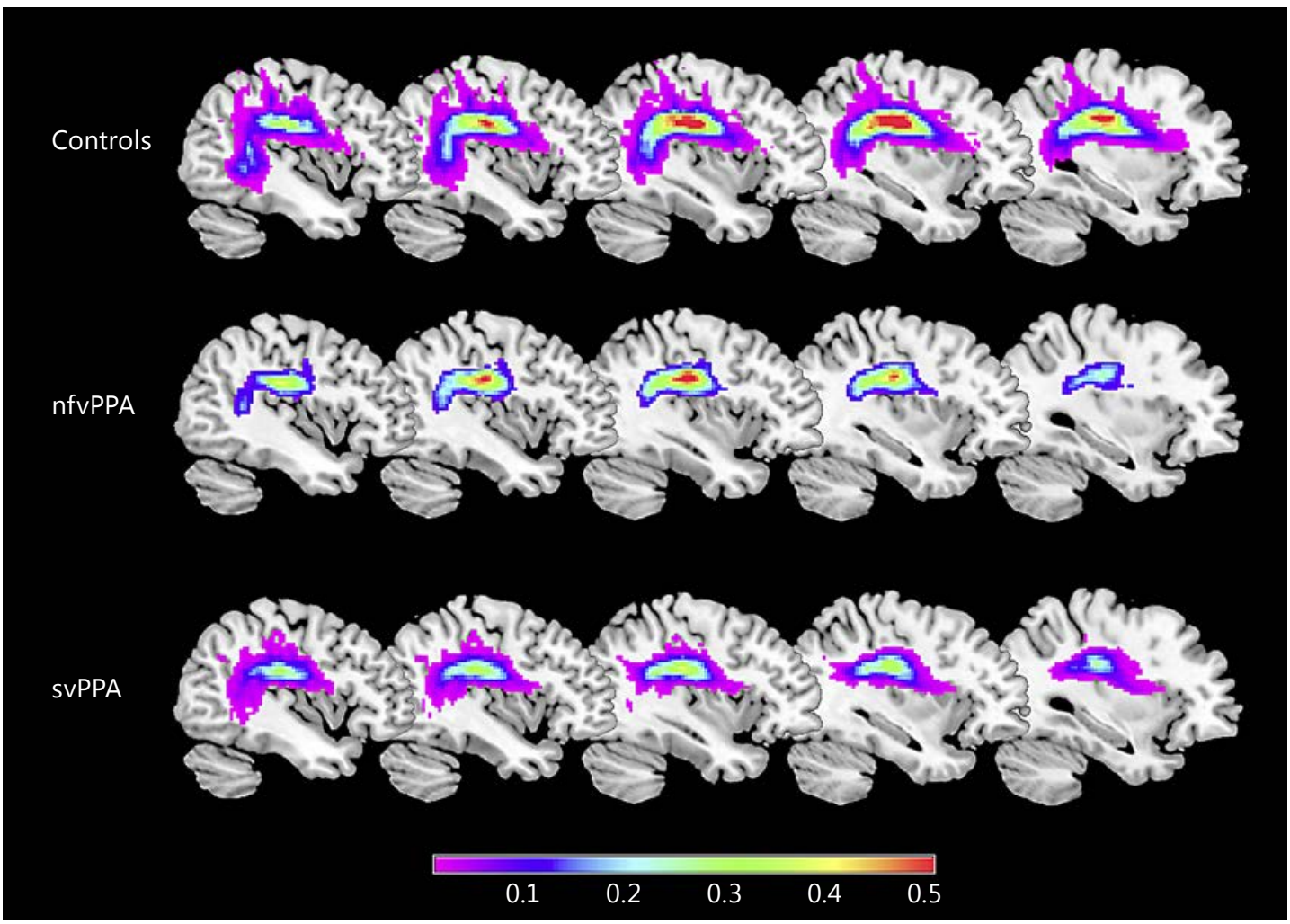

Fig. 2. FA maps of the left dorsal stream (SLF) of the control, nfvPPA, and svPPA groups overlaid on a standard MNI brain. Only voxels present in at least $20 \%$ of the participants are shown. Lower FA values are represented in violet-blue, and higher values are represented in yellow-red.

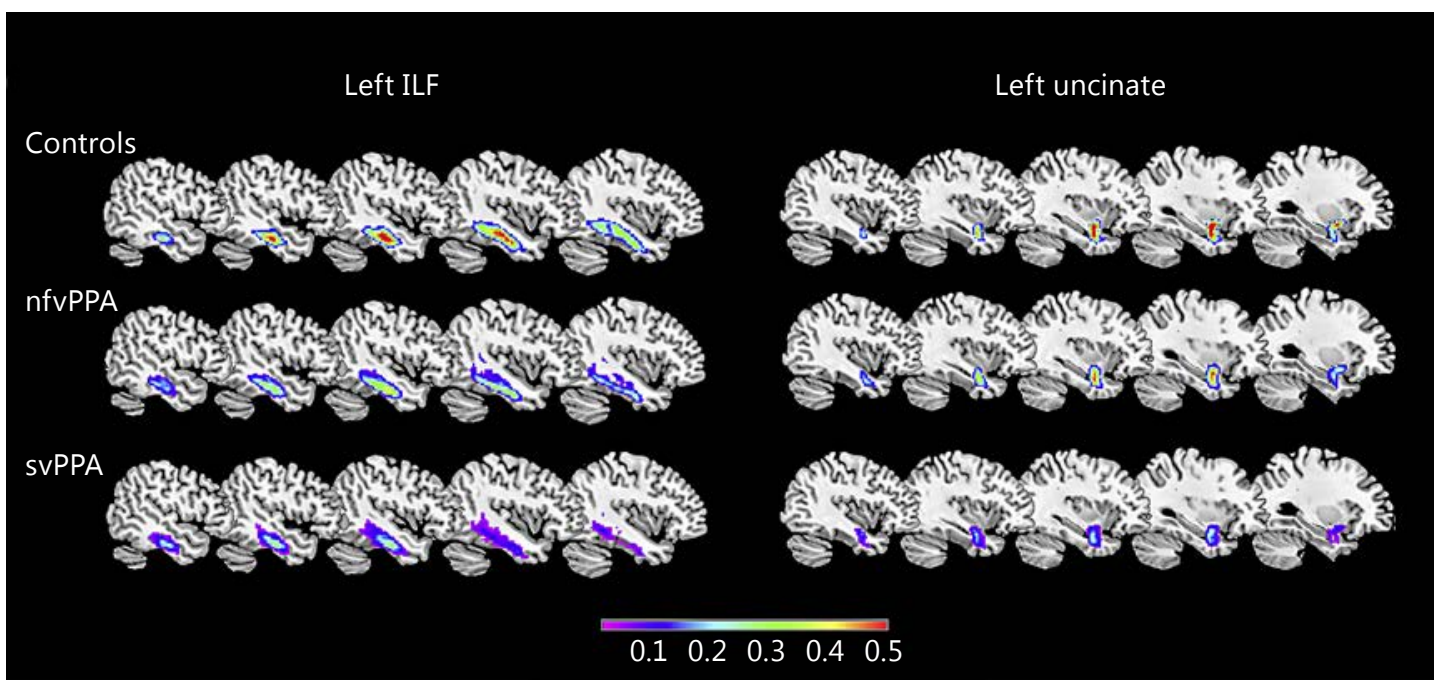

Fig. 3. FA maps of the left ventral stream (ILF and uncinate) of the control, nfvPPA, and svPPA groups overlaid on a standard MNI brain. Only voxels present in at least $20 \%$ of the participants are shown. Lower FA values are represented in violet-blue, and higher values are represented in yellow-red. 


\section{Correlations between DTI Metrics and Connected Speech Factors}

We found significant partial correlations, using NBV as covariate, with two semantic factors (only) - namely Factors 3 and 5 (see Fig. 4). For Factor 3, positive correlations were found with FA in the left ILF ( $p=0.024, r=0.348$ ) and in the left SLF ( $p=0.039, r=0.320$ ). Moreover, negative correlations were found between Factor 3 and RD in the left ILF ( $p=$ $0.003, r=-0.442)$ and in the left SLF ( $p=0.007, r=-0.410)$. For Factor 5 , negative correlations were found with RD in the left ILF ( $p=0.046, r=-0.310)$, the right ILF ( $p=0.049, r=$ $-0.306)$, and right uncinate ( $p=0.019, r=-0.362)$.

Correlations between DTI Metrics and Language Measures That Distinguished the Groups

To investigate the relationship between semantic processing and DTI metrics, partial correlations between the PPVT and FA and RD were computed. Significant negative correlations were found for the PPVT with RD in the left uncinate $(p<0.001, r=-0.576)$ as well as in the left ILF ( $p<0.001, r=-0.692)$. Similarly, partial correlations between the verb story completion task and FA and RD were computed to investigate the relationship between verb processing in sentences, which was significantly more impaired in nfvPPA than in svPPA patients, and tract specific measurements. A negative correlation was found between the verb story completion score and RD in the left SLF ( $p<0.05, r=-0.349)$.

Finally, we investigated whether the factors obtained from the PCA were correlated with their respective, distinguishing language evaluation measures. We found a significant correlation between the PPVT and the lexical richness factor (Factor 3) scores $(p<0.001, r=0.547)$. However, scores on the verb story completion task were not significantly correlated with either syntactic factor.

\section{Discussion}

This study was designed to assess the relationship between white matter damage and connected speech features in nfvPPA and svPPA. Although the finding of differences in connected speech between the patient groups was minimal, the PCA factor structure allowed us to identify five factors that were related to the tasks. More importantly, one of the two syntactic factors distinguished the nfvPPA patients from the controls, whereas one of the three semantic factors distinguished the svPPA patients from the controls. In accordance with previous studies [1, 32-35, 39], the nfvPPA group showed DTI diffusivity changes only in the left dorsal language pathway, whereas the svPPA group showed widespread damage to the ventral tracts bilaterally as well as to the left SLF. Ventral damage in the svPPA group distinguished them from the non-fluent group. Significant correlations between the left ILF and two semantic factors in connected speech were obtained. In addition, significant negative correlations between receptive semantic processing (i.e. the PPVT) and RD in the two left ventral fibre bundles were obtained. Neither of the syntactic factors extracted from connected speech correlated significantly with the DTI metrics, but verb story completion scores were correlated with RD in the left SLF.

Fig. 4. Significant partial correlations between connected speech features and DTI metrics for each patient group. There are extreme values for 2 svPPA patients. Nonetheless, the data from these two patients were kept after a close look at all the DTI metrics as well as the neuropsychological and language evaluations, which did not suggest that these 2 patients were outliers. UNC = Uncinate. 
$E X T R A$

Dementia

and Geriatric

Cognitive Disorders
Dement Geriatr Cogn Disord Extra

(c) 2017 The Author(s). Published by S. Karger AG, Basel www.karger.com/dee

Marcotte et al.: White Matter Disruption and Connected Speech
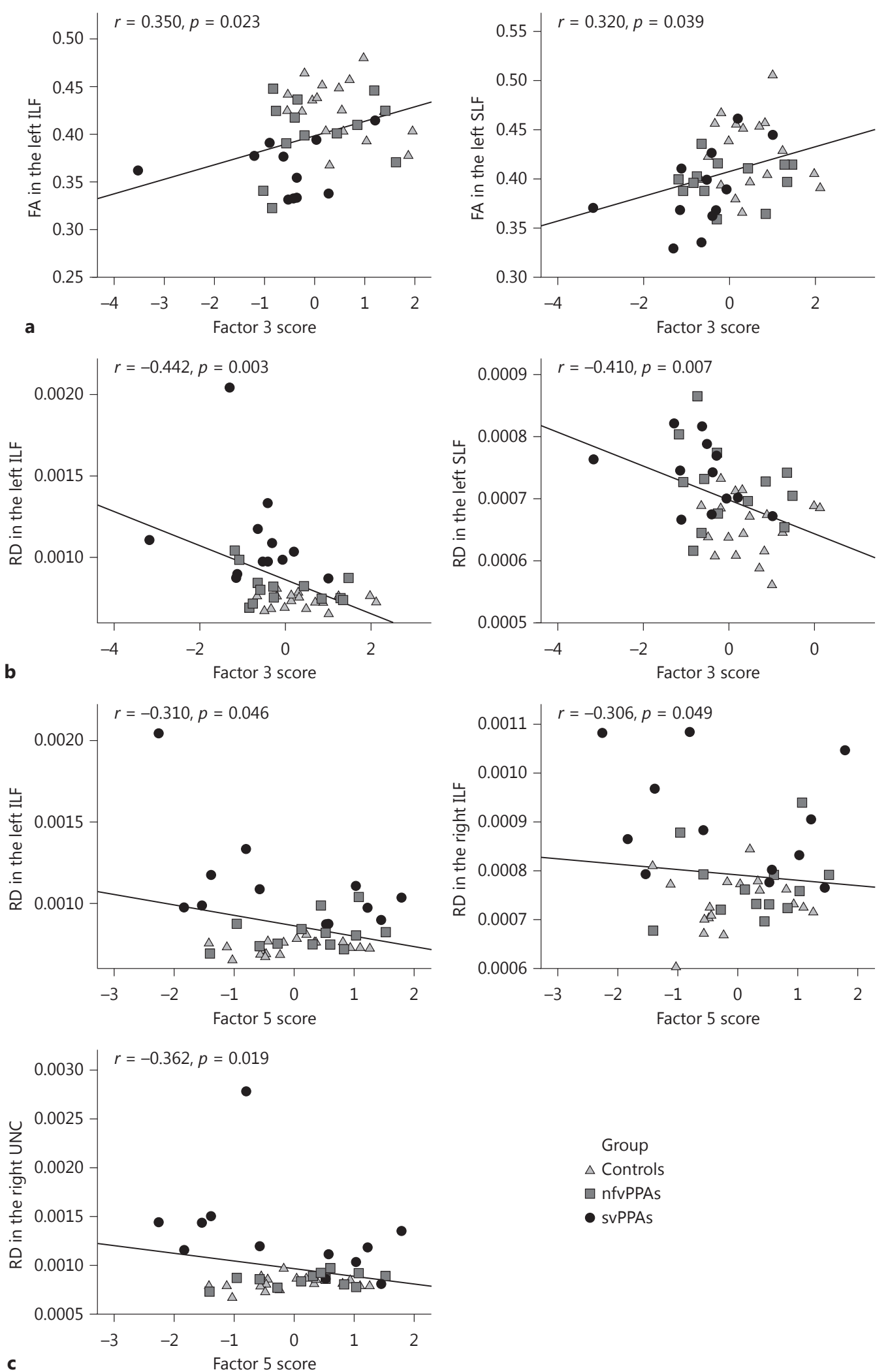

Group

$\triangle$ Controls

$\square$ nfvPPAs

- svPPAs

Factor 5 score 


\section{Connected Speech Features}

The two PPA groups exhibited linguistic deficits on neuropsychological testing which are consistent with those seen in each variant in previous studies, but on the measures of connected speech, only words per minute distinguished the two variants from each other. Speaking rate seems to be the most consistent feature distinguishing the semantic and the non-fluent variants with respect to connected speech [15, 16, 23, 24, 26]. Other differentiating, lexico-semantic, or syntactic features vary between studies. One might have expected that nfvPPA patients would have produced shorter sentences than svPPA patients, but to our knowledge only one study has reported this finding [16]. Most studies on connected/conversational speech have, however, found that the mean length of an utterance was shorter in nfvPPA patients than in healthy controls $[23,26]$, which is also what we found.

The nature of the elicitation task may explain the lack of difference between the nonfluent and semantic variants on connected speech features in the current study. Similarly, a syntactic impairment may be less apparent on this task than on a more complicated narrative task (like re-telling the Cinderella story) or a constrained production task. Discourse production as in the topic-directed interviews used here does not provide obligatory contexts for production. In contrast, constrained production tasks may be more difficult because the target verb and morphemes are prescribed. For example, in an earlier study involving a subgroup of the patients reported here, we found that nfvPPA patients performed significantly more poorly on a verb story completion task than svPPA patients [66]. Thus, impairment in grammatical abilities per se may not be revealed in an unconstrained context such as topicdirected interviews. We may not have found differences between the patient groups because of the nature of the task, which allows patients to discuss familiar topics using familiar vocabulary. This is almost certainly less semantically taxing than other connected speech tasks (like re-telling the Cinderella story or picture description), and, therefore, the semantic impairment in the svPPA patients may be less apparent. In order to reduce the number of correlations and optimize power, a PCA was conducted. Interestingly, although the number of participants was relatively small, the PCA yielded 5 factors that characterized the task. Among these factors, the syntactic factor that measured sentence complexity and subordination distinguished the nfvPPA patients from the controls, whereas the lexical richness factor distinguished the svPPA patients from the controls. Although the present findings did not differentiate the two variants, our results showed that this approach can distinguish between the healthy controls and each of the two patient groups.

One might have expected that more features would have discriminated the two PPA variants. To confirm that this was not an artefact of the automated analyses, we compared the results with scores obtained on manually performed Quantitative Production Analysis [49]. The results replicated the automated analysis, and words per minute was the only measure that distinguished the two variants. We used speech samples of 100 narrative words, which was consistent with other studies that have used short speech samples and reported reliable group differences $[10,22,26,48]$. However, we might have found a greater number of significant differences between the patient groups had we used longer speech samples.

\section{DTI Metrics}

In accordance with previous studies [1, 32-35, 39], we found significant white matter changes in tracts that are known to play a role in language processing in both the svPPA and nfvPPA groups. The key role of the SLF in syntactic processing has been well documented [e.g. $39,71]$ by robust correlations between reduced FA and syntactic comprehension and production [39]. In the present study, none of the syntactic factors significantly distinguished between the svPPA and nfvPPA groups, and so we were unable to test the role of the SLF in syntactic processing in connected speech. Nevertheless, we found further evidence for the 
importance of the SLF in verb processing as observed by the significant correlation between verb story completion and RD in the left SLF. In addition to the proposed role of the SLF in syntactic processing, there is also evidence to suggest that it is involved in semantic processing $[72,73]$. The present results tend to support this idea as the lexical richness factor was correlated with FA and RD in the left SLF.

The results of the present study demonstrated that SVPPA is mainly characterized by bilateral damage in the ventral tracts (i.e., the uncinate and the ILF), which is consistent with findings of previous DTI studies [32-35]. Interestingly, the lexical richness factor and the semantic representations factor were both significantly correlated with the left ILF. We also found a negative correlation between the RD in the left ILF and single-word comprehension. Unlike the role of the uncinate fasciculus in language, the role of the ILF is more controversial. Saur et al. [74] and Vigneau et al. [75] suggest that the ILF mediates semantic processing. In particular, Vigneau et al. [75] propose that a two-step pathway supports semantic processing involving processing in the ILF and then relayed by the uncinate fasciculus. However, to our knowledge, no previous studies have reported significant correlations between lexical richness in on-line production, single-word comprehension, and white matter damage in the left ILF in either PPA or in stroke-induced aphasia. At present, we cannot rule out the possibility that the effect could be driven principally by the performance of patients with the semantic variant, but it provides evidence that semantic impairment in connected speech production is also related to white matter damage in the left ILF.

\section{Limitations}

Two limitations of our study should be noted. First, the SLF has multiple subcomponents [76-78], which can be damaged differently in the different PPA variants [33]. We used the same ROIs as described in Galantucci et al. [33] for the whole SLF, which were also used in Wilson et al. [39] but reported as the SLF/arcuate. Second, as noted in Schwindt et al. [35], our acquisition protocol only includes 23 separate gradient directions, which is likely to be stable for FA above 20 directions, but which might not be optimal for a robust estimation of tensor orientation [79]. While this may have added variance to measures of diffusivity, we were nonetheless able to detect group differences in RD measures. Additionally, the Dementia Rating Scale is significantly lower in patients with svPPA than in those with nfvPPA, which may suggest that patients with svPPA were more severely impaired than those with nfvPPA. This difference in terms of level of severity might also explain the lack of difference on grammatical, fluency, and lexico-semantic measures as well as on the five components extracted from the PCA. The variability in the progression of brain atrophy observed in patients with svPPA [21] might also explain the finding that only one feature, words per minute, distinguished the connected speech of the two patient groups of this cohort.

\section{Conclusions}

Analyses of connected speech showed that nfvPPA patients were impaired relative to healthy controls on syntactic measures, whereas the svPPA group was impaired relative to controls on lexico-semantic measures. The only feature that distinguished the patient groups from each other was speech rate. Probabilistic tractography provided evidence that structural compromise to multiple tracts was associated with language impairments in patients with PPA. Our findings suggest that semantic deficits in connected speech in PPA may reflect not only grey matter damage, but also disruption of the ventral white matter pathway. If confirmed in future samples (currently in progress), the combination of an automated approach and PCA could provide a faster but still thorough method of analyzing connected speech in PPA. 


\section{Acknowledgments}

The authors thank Chris Scott for assistance with imaging support, Isabel Lam for study coordination, and Amy Lewis, Shayna Sparling, Danna Rybko, Inderjit Sohal, and Ashleigh Wishen for help with testing participants. Morris Freedman receives support from the Saul A. Silverman Family Foundation as a Canada International Scientific Exchange Program and the Morris Kerzner Memorial Fund.

\section{Disclosure Statement}

Morris Freedman received honoraria from Eli Lilly Canada Inc. for participating in consultancy and advisory board meetings. He is also listed on a provisional patent related to methods and kits for differential diagnosis of Alzheimer disease versus frontotemporal dementia using blood biomarkers and may be listed on the planned patent application. The other authors declare that they have no competing interests.

\section{Funding Sources}

This research was supported by grants from the Canadian Institutes of Health Research (CIHR 82744 and 130462) to E.R., S.E.B., C.L., N.L.G., K.M., D.T.W., and T.W.C.; from the Toronto Rehabilitation Institute (to K.M.); and from the Department of Medicine at the University of Toronto and Sunnybrook Health Sciences Center, the Brill Chair in Neurology, the L.C. Campbell Cognitive Neurology Research Unit, Hurvitz Brain Sciences Research Program, and Sunnybrook Research Institute (to S.E.B.).

\section{References}

1 Gorno-Tempini ML, Dronkers NF, Rankin KP, Ogar JM, Phengrasamy L, Rosen HJ, Johnson JK, Weiner MW, Miller BL: Cognition and anatomy in three variants of primary progressive aphasia. Ann Neurol 2004;55: 335-346.

2 Mesulam MM: Slowly progressive aphasia without generalized dementia. Ann Neurol 1982;11:592-598.

-3 Graham NL, Patterson K, Hodges JR: The impact of semantic memory impairment on spelling: evidence from semantic dementia. Neuropsychologia 2000;38:143-163.

4 Graham NL, Patterson K, Hodges JR: The emergence of jargon in progressive fluent dysgraphia: the widening gap between target and response. Cogn Neuropsychol 2001;18:343-361.

5 Hillis AE, Oh S, Ken L: Deterioration of naming nouns versus verbs in primary progressive aphasia. Ann Neurol 2004;55:268-275.

6 Brambati SM, Ogar J, Neuhaus J, Miller BL, Gorno-Tempini ML: Reading disorders in primary progressive aphasia: a behavioral and neuroimaging study. Neuropsychologia 2009;47:1893-1900.

7 Wilson SM, Brambati SM, Henry RG, Handwerker DA, Agosta F, Miller BL, Wilkins DP, Ogar JM, Gorno-Tempini ML: The neural basis of surface dyslexia in semantic dementia. Brain 2009;132:71-86.

-8 Taylor C, Croot K, Power E, Savage SA, Hodges JR, Togher L: Trouble and repair during conversations of people with primary progressive aphasia. Aphasiology 2014;28:1069-1091.

-9 Le Rhun E, Richard F, Pasquier F: Natural history of primary progressive aphasia. Neurology 2005;65:887891.

10 Graham NL, Patterson K, Hodges JR: When more yields less: speaking and writing deficits in nonfluent progressive aphasia. Neurocase 2004;10:141-155.

11 Tingley SJ, Kyte CS, Johnson CJ, Beitchman JH: Single-word and conversational measures of word-finding proficiency. Am J Speech Lang Pathol 2003;12:359-368.

12 Wilshire CE, McCarthy RA: Evidence for a context-sensitive word retrieval disorder in a case of nonfluent aphasia. Cogn Neuropsychol 2002;19:165-186. 
13 Knibb JA, Woollams AM, Hodges JR, Patterson K: Making sense of progressive non-fluent aphasia: an analysis of conversational speech. Brain 2009;132:2734-2746.

14 Thompson CK, Meltzer-Asscher A, Cho S, Lee J, Wieneke C, Weintraub S, Mesulam MM: Syntactic and morphosyntactic processing in stroke-induced and primary progressive aphasia. Behav Neurol 2013;26:35-54.

15 Ash S, Moore P, Vesely L, Gunawardena D, McMillan C, Anderson C, Avants B, Grossman M: Non-Fluent speech in frontotemporal lobar degeneration. J Neurolinguistics 2009;22:370-383.

16 Wilson SM, Henry ML, Besbris M, Ogar JM, Dronkers NF, Jarrold W, Miller BL, Gorno-Tempini ML: Connected speech production in three variants of primary progressive aphasia. Brain 2010;133:2069-2088.

-17 Ash S, Moore P, Antani S, McCawley G, Grossman M: Quantitative analysis of grammatical deviance in frontotemporal disease. Brain Lang 2005;95:155-156.

18 Kavé G, Leonard C, Cupit J, Rochon E: Structurally well-formed narrative production in the face of severe conceptual deterioration: a longitudinal case study of a woman with semantic dementia. J Neurolinguistics 2007;20:161-177.

19 Meteyard L, Patterson K: The relation between content and structure in language production: an analysis of speech errors in semantic dementia. Brain Lang 2009;110:121-134.

-20 Fraser KC, Meltzer JA, Graham NL, Leonard C, Hirst G, Black SE, Rochon E: Automated classification of primary progressive aphasia subtypes from narrative speech transcripts. Cortex 2014;55:43-60.

-21 Bright P, Moss HE, Stamatakis EA, Tyler LK: Longitudinal studies of semantic dementia: the relationship between structural and functional changes over time. Neuropsychologia 2008;46:2177-2188.

22 Patterson K, MacDonald MC: Sweet nothings: narrative speech in semantic dementia; in Andrews S (ed): From Inkmarks to Ideas: Current Issues in Lexical Processing. Hove, Psychology Press, 2006.

23 Ash S, Moore P, Antani S, McCawley G, Work M, Grossman M: Trying to tell a tale: discourse impairments in progressive aphasia and frontotemporal dementia. Neurology 2006;66:1405-1413.

24 Mack JE, Chandler SD, Meltzer-Asscher A, Rogalski E, Weintraub S, Mesulam MM, Thompson CK: What do pauses in narrative production reveal about the nature of word retrieval deficits in PPA? Neuropsychologia 2015;77:211-222.

-25 Pakhomov SV, Smith GE, Chacon D, Feliciano Y, Graff-Radford N, Caselli R, Knopman DS: Computerized analysis of speech and language to identify psycholinguistic correlates of frontotemporal lobar degeneration. Cogn Behav Neurol 2010;23:165-177.

26 Thompson CK, Cho S, Hsu CJ, Wieneke C, Rademaker A, Weitner BB, Mesulam MM, Weintraub S: Dissociations between fluency and agrammatism in primary progressive aphasia. Aphasiology 2012;26:20-43.

-27 Lambon Ralph MA, Graham KS, Ellis AW, Hodges JR: Naming in semantic dementia - what matters? Neuropsychologia 1998;36:775-784.

28 Woollams AM, Cooper-Pye E, Hodges JR, Patterson K: Anomia: a doubly typical signature of semantic dementia. Neuropsychologia 2008;46:2503-2514.

29 Agosta F, Galantucci S, Canu E, Cappa SF, Magnani G, Franceschi M, Falini A, Comi G, Filippi M: Disruption of structural connectivity along the dorsal and ventral language pathways in patients with nonfluent and semantic variant primary progressive aphasia: a DT MRI study and a literature review. Brain Lang 2013;127:157-166.

30 Grossman M, Powers J, Ash S, McMillan C, Burkholder L, Irwin D, Trojanowski JQ: Disruption of large-scale neural networks in non-fluent/agrammatic variant primary progressive aphasia associated with frontotemporal degeneration pathology. Brain Lang 2013;127:106-120.

31 Sajjadi SA, Acosta-Cabronero J, Patterson K, Diaz-de-Grenu LZ, Williams GB, Nestor PJ: Diffusion tensor magnetic resonance imaging for single subject diagnosis in neurodegenerative diseases. Brain 2013;136: 2253-2261.

-32 Agosta F, Scola E, Canu E, Marcone A, Magnani G, Sarro L, Copetti M, Caso F, Cerami C, Comi G, Cappa SF, Falini A, Filippi M: White matter damage in frontotemporal lobar degeneration spectrum. Cereb Cortex 2012;22: 2705-2714.

-33 Galantucci S, Tartaglia MC, Wilson SM, Henry ML, Filippi M, Agosta F, Dronkers NF, Henry RG, Ogar JM, Miller BL, Gorno-Tempini ML: White matter damage in primary progressive aphasias: a diffusion tensor tractography study. Brain 2011;134:3011-3029.

-34 Mahoney CJ, Malone IB, Ridgway GR, Buckley AH, Downey LE, Golden HL, Ryan NS, Ourselin S, Schott JM, Rossor MN, Fox NC, Warren JD: White matter tract signatures of the progressive aphasias. Neurobiol Aging 2013;34:1687-1699.

35 Schwindt GC, Graham NL, Rochon E, Tang-Wai DF, Lobaugh NJ, Chow TW, Black SE: Whole-brain white matter disruption in semantic and nonfluent variants of primary progressive aphasia. Hum Brain Mapp 2013;34: 973-984.

-36 Catani M, Mesulam MM, Jakobsen E, Malik F, Martersteck A, Wieneke C, Thompson CK, Thiebaut de Schotten M, Dell'Acqua F, Weintraub S, Rogalski E: A novel frontal pathway underlies verbal fluency in primary progressive aphasia. Brain 2013;136:2619-2628.

37 Mandelli ML, Caverzasi E, Binney RJ, Henry ML, Lobach I, Block N, Amirbekian B, Dronkers N, Miller BL, Henry RG, Gorno-Tempini ML: Frontal white matter tracts sustaining speech production in primary progressive aphasia. J Neuroscience 2014;34:9754-9767.

-38 Powers JP, McMillan CT, Brun CC, Yushkevich PA, Zhang H, Gee JC, Grossman M: White matter disease correlates with lexical retrieval deficits in primary progressive aphasia. Front Neurol 2013;4:212. 
-39 Wilson SM, Galantucci S, Tartaglia MC, Rising K, Patterson DK, Henry ML, Ogar JM, DeLeon J, Miller BL, GornoTempini ML: Syntactic processing depends on dorsal language tracts. Neuron 2011;72:397-403.

40 Gorno-Tempini ML, Hillis AE, Weintraub S, Kertesz A, Mendez M, Cappa SF, Ogar JM, Rohrer JD, Black S, Boeve BF, Manes F, Dronkers NF, Vandenberghe R, Rascovsky K, Patterson K, Miller BL, Knopman DS, Hodges JR, Mesulam MM, Grossman M: Classification of primary progressive aphasia and its variants. Neurology 2011;76: 1006-1014.

41 Kaplan E, Goodglass H, Weintraub S: Boston Naming Test. Philadelphia, Lippincott Williams \& Wilkins, 2001.

42 Dunn LM, Dunn LM: Peabody Picture Vocabulary Test. Circle Pines, American Guidance Services Publishing, 1997.

43 Howard D, Patterson K: The Pyramids and Palm Trees Test: A Test for Semantic Access from Words and Pictures. Bury St. Edmunds, Thames Valley Test Company, 1992.

44 Barde LH, Schwartz MF, Boronat CB: Semantic weight and verb retrieval in aphasia. Brain Lang 2006;97:266278.

45 Breedin SD, Saffran EM, Schwartz MF: Semantic factors in verb retrieval: an effect of complexity. Brain Lang 1998;63:1-31.

46 Bishop DVM: Test for the Reception of Grammar. London, Psychological Corporation, 2003.

47 Orange JB, Kertesz A, Peacock J: Pragmatics in frontal lobe dementia and primary progressive aphasia. J Neurolinguistics 1998;11:153-177.

48 Bird H, Lambon Ralph MA, Patterson K, Hodges JR: The rise and fall of frequency and imageability: noun and verb production in semantic dementia. Brain Lang 2000;73:17-49.

49 Berndt RS, Wayland S, Rochon E, Saffran E, Schwartz M: Quantitative Production Analysis: A Training Manual for the Analysis of Aphasic Sentence Production. Hove, Psychology Press, 2000.

50 Bucks RS, Singh S, Cuerden JM, Wilcock GK: Analysis of spontaneous conversational speech in dementia of Alzheimer type: evaluation of an objective technique for analysing lexical performance. Aphasiology 2000;14: 71-91.

51 Brunét E: Le vocabulaire de Jean Giraudoux. Structure et évolution. Genève, Slatkine, 1978.

52 Honoré A: Some simple measures of richness of vocabulary. Association for Literary and Linguistic Computing Bulletin 1979;7:172-177.

53 Douaud G, Smith S, Jenkinson M, Behrens T, Johansen-Berg H, Vickers J, James S, Voets N, Watkins K, Matthews PM, James A: Anatomically related grey and white matter abnormalities in adolescent-onset schizophrenia. Brain 2007;130:2375-2386.

54 Good CD, Johnsrude IS, Ashburner J, Henson RN, Friston KJ, Frackowiak RS: A voxel-based morphometric study of ageing in 465 normal adult human brains. Neurolmage 2001;14:21-36.

55 Smith SM, Jenkinson M, Woolrich MW, Beckmann CF, Behrens TE, Johansen-Berg H, Bannister PR, De Luca M, Drobnjak I, Flitney DE, Niazy RK, Saunders J, Vickers J, Zhang Y, De Stefano N, Brady JM, Matthews PM: Advances in functional and structural MR image analysis and implementation as FSL. NeuroImage 2004;23 Suppl 1:S208-219.

56 Andersson J, Jenkinson M, Smith S: Non-Linear Optimisation FMRIB Technical Report TR07JA1. Oxford, FMRIB Centre, 2007,

-57 Behrens TE, Woolrich MW, Jenkinson M, Johansen-Berg H, Nunes RG, Clare S, Matthews PM, Brady JM, Smith SM: Characterization and propagation of uncertainty in diffusion-weighted MR imaging. Magn Reson Med 2003;50:1077-1088.

-58 Behrens TE, Berg HJ, Jbabdi S, Rushworth MF, Woolrich MW: Probabilistic diffusion tractography with multiple fibre orientations: What can we gain? NeuroImage 2007;34:144-155.

-59 Jezzard P, Barnett AS, Pierpaoli C: Characterization of and correction for eddy current artifacts in echo planar diffusion imaging. Magn Reson Med 1998;39:801-812.

60 Behrens TE, Woolrich MW, Jenkinson M, Johansen-Berg H, Nunes RG, Clare S, Matthews PM, Brady JM, Smith SM: Characterization and propagation of uncertainty in diffusion-weighted MR imaging. Magn Reson Med 2003;50:1077-1088.

61 Acosta-Cabronero J, Williams GB, Pengas G, Nestor PJ: Absolute diffusivities define the landscape of white matter degeneration in Alzheimer's disease. Brain 2010;133:529-539.

-62 Zhang Y, Tartaglia MC, Schuff N, Chiang GC, Ching C, Rosen HJ, Gorno-Tempini ML, Miller BL, Weiner MW: MRI signatures of brain macrostructural atrophy and microstructural degradation in frontotemporal lobar degeneration subtypes. J Alzheimers Dis 2013;33:431-444.

63 Basser PJ, Mattiello J, LeBihan D: MR diffusion tensor spectroscopy and imaging. Biophys J 1994;66:259-267.

64 Costello AB, Osborne JW: Best practices in exploratory factor analysis: four recommendations for getting the most from your analysis. Practical Assess Res Eval 2005;10:1-9.

-65 Smith SM, Zhang Y, Jenkinson M, Chen J, Matthews PM, Federico A, De Stefano N: Accurate, robust, and automated longitudinal and cross-sectional brain change analysis. NeuroImage 2002;17:479-489.

66 Marcotte K, Graham NL, Black SE, Tang-Wai D, Chow T, Freedman M, Leonard C, Rochon E: Verb production in non-fluent primary progressive aphasia and semantic dementia: the influence of lexical and semantic factors. Cogn Neuropsychol 2014;31:565-583.

-67 Gorno-Tempini ML, Ogar JM, Brambati SM, Wang P, Jeong JH, Rankin KP, Dronkers NF, Miller BL: Anatomical correlates of early mutism in progressive nonfluent aphasia. Neurology 2006;67:1849-1851. 
Mesulam MM, Rogalski EJ, Wieneke C, Hurley RS, Geula C, Bigio EH, Thompson CK, Weintraub S: Primary progressive aphasia and the evolving neurology of the language network. Nat Rev Neurol 2014;10:554-569.

69 Mummery CJ, Patterson K, Price CJ, Ashburner J, Frackowiak RS, Hodges JR: A voxel-based morphometry study of semantic dementia: relationship between temporal lobe atrophy and semantic memory. Ann Neurol 2000;47:36-45.

70 Nestor PJ, Graham NL, Fryer TD, Williams GB, Patterson K, Hodges JR: Progressive non-fluent aphasia is associated with hypometabolism centred on the left anterior insula. Brain 2003;126:2406-2418.

71 Friederici AD: Pathways to language: fiber tracts in the human brain. Trends Cogn Sci 2009;13:175-181.

72 Glasser MF, Rilling JK: DTI tractography of the human brain's language pathways. Cereb Cortex 2008;18: 2471-2482.

73 Yeatman JD, Dougherty RF, Rykhlevskaia E, Sherbondy AJ, Deutsch GK, Wandell BA, Ben-Shachar M: Anatomical properties of the arcuate fasciculus predict phonological and reading skills in children. J Cogn Neurosci 2011;23:3304-3317.

74 Saur D, Kreher BW, Schnell S, Kummerer D, Kellmeyer P, Vry MS, Umarova R, Musso M, Glauche V, Abel S, Huber W, Rijntjes M, Hennig J, Weiller C: Ventral and dorsal pathways for language. Proc Natl Acad Sci USA 2008;105:18035-18040.

75 Vigneau M, Beaucousin V, Herve PY, Duffau H, Crivello F, Houde O, Mazoyer B, Tzourio-Mazoyer N: Metaanalyzing left hemisphere language areas: phonology, semantics, and sentence processing. NeuroImage 2006;30:1414-1432.

76 Catani M, Jones DK, ffytche DH: Perisylvian language networks of the human brain. Ann Neurol 2005;57:8-16.

77 Frey S, Campbell JS, Pike GB, Petrides M: Dissociating the human language pathways with high angular resolution diffusion fiber tractography. J Neurosci 2008;28:11435-11444.

78 Makris N, Kennedy DN, McInerney S, Sorensen AG, Wang R, Caviness VS, Jr, Pandya DN: Segmentation of subcomponents within the superior longitudinal fascicle in humans: a quantitative, in vivo, DT-MRI study. Cereb Cortex 2005;15:854-869.

79 Jones DK: The effect of gradient sampling schemes on measures derived from diffusion tensor MRI: a Monte Carlo study. Magn Reson Med 2004;51:807-815. 